\section{Cureus}

Received 05/24/2018

Review began 06/19/2018

Review ended 09/08/2018

Published 09/11/2018

\section{(c) Copyright 2018}

Atanda et al. This is an open access article distributed under the terms of the Creative Commons Attribution License CC-BY 3.0., which permits unrestricted use, distribution, and reproduction in any medium, provided the original author and source are credited.

\title{
Hyperuricemia-associated Mesoamerican Nephropathy: Case Report and Review of Literature
}

Adebayo Atanda ${ }^{1}$, Janna Henry ${ }^{1}$, Gbeminiyi Samuel ${ }^{2}$, Olusayo Fadiran ${ }^{3}$, Curtis Frederick ${ }^{1}$, Oluwatosin Omole ${ }^{4}$, Kolapo Idowu ${ }^{5}$, C C. Mere ${ }^{6}$

1. Internal Medicine, Howard University Hospital, Washington, D.C., USA 2. Internal Medicine, Howard University Hospital, Hyattsville, USA 3. Medicine, Howard University Hospital, Washington, D.C., USA 4. Family Medicine, Howard University Hospital, Washington, D.C., USA 5. Family Medicine, Howard University Hospital, Orlando, USA 6. Nephrology Unit, Howard University Hospital, Washington, D.C., USA

$\square$ Corresponding author: Janna Henry, janhenry@huhosp.org

Disclosures can be found in Additional Information at the end of the article

\section{Abstract}

Mesoamerican nephropathy (MeN), formerly called chronic kidney disease of unknown cause $(\mathrm{CKDu})$, refers to chronic kidney disease (CKD) that presents in young and middle-aged Central Americans in the absence of any clear etiology. MeN is a relatively new diagnosis with rapidly rising prevalence in specific regions of El Salvador and Nicaragua, Guatemala, and Costa Rica. It is seldom associated with hyperuricemia. We present a case of a patient with gouty arthritis and hyperuricemia with associated CKD due to MeN. We also provide a review of literature of this disease.

Categories: Internal Medicine, Nephrology, Rheumatology

Keywords: gout, mesoamerican nepropathy, ckd, hyperuricemia, nephropathy, aki, uric acid

\section{Introduction}

Mesoamerican nephropathy (MeN) was first described in El Salvadorian patients when it was noted that a high percentage of patients were initiated on dialysis with no possible etiology of chronic kidney disease (CKD) [1-3]. Various risk factors have been described including agricultural and physically demanding work, pesticide. Nonsteroidal anti-inflammatory drugs (NSAIDs) and lower socioeconomic class are also important underlying risk factors for MeN $[4,5]$. There is a paucity of reported cases of hyperuricemia-associated MeN. We report a 41year-old man with this condition and delved into a thorough review of literature on this relatively novel disease.

\section{Case Presentation}

We report a 41-year-old man with history of hyperuricemia and gouty arthritis who presented with progressive dyspnea of three days duration. The patient endorsed multiple painful swelling in his hands and elbow with limitation of motion. He also mentioned new lesions in his ear lobes. The patient is a former smoker with 10 pack year history. He worked as agricultural field laborer and truck driver in El Salvador for six years before immigrating to the United States. Review of system is positive for nocturia.

Examination revealed pale and icteric gentleman with yellowish deposits in both ear lobes 


\section{Cureus}

(Figure 1). Auscultation revealed bi-basilar fine crackles. Also, the patient had joint swelling and deformity associated with hotness and redness in his right elbow, right and left hand, proximal interphalangeal joint, distal interphalangeal joint, and metacarpophalangeal joint (Figure 1). Swellings were mildly tender to palpation. Important labs on admission include blood urea nitrogen (BUN) of 65, creatinine of 8.6 and hemoglobin of 6.8. Extensive laboratory and radiologic investigations for causative factors for CKD were negative. He was subsequently started on hemodialysis following worsening renal function. During the course of admission, he was treated for an acute flare of gouty arthritis of his right great toe with renally dosed colchicine. Also, an arterio-venous fistula was secured before discharge.

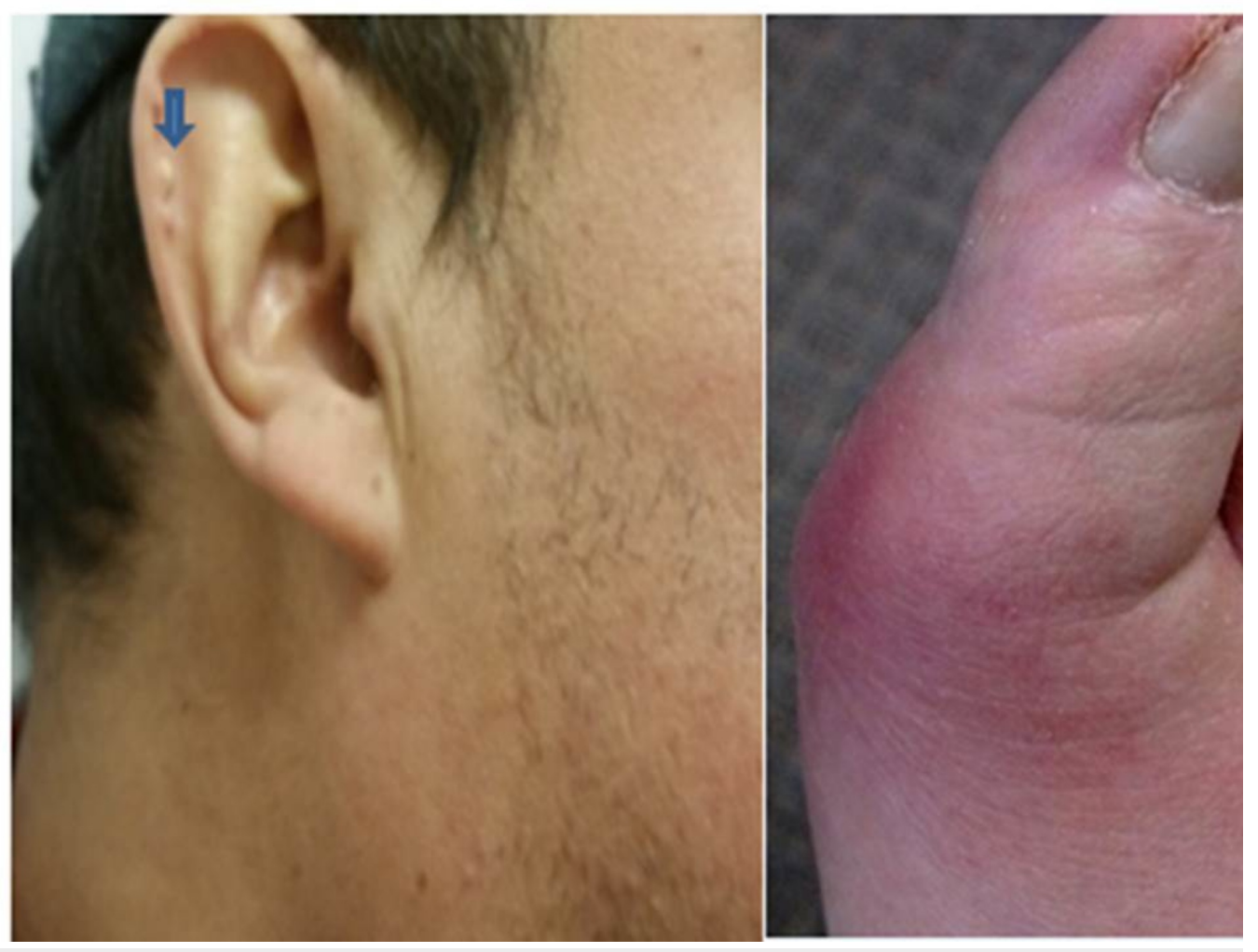

FIGURE 1: Left: Right Pinna Tophi (blue arrow); Right: Gouty flare of right first metatarsophalangeal joint.

\section{Discussion}

MeN, formerly called CKDu, refers to CKD that presents in young, agricultural workers in Central America and other tropical parts of the world, in the absence of any clear etiology $[4,5]$. Most patients have a history of physically demanding agricultural work in a hot climate [6].

Although the etiology of MeN is still unclear, hard physical work in hot climates appears to be the most important underlying risk factor [4,5]. High temperatures predispose to dehydration, volume depletion, and loss of minerals and may precipitate rhabdomyolysis. Prolonged working under high temperature may result in cyclic uricosuria in which uric acid concentrations exceed solubility, leading to the formation of dihydrate urate crystals and local injury from the direct cytotoxic effect of the increased urinary uric acid on renal tubules [1,6]. Another proposed mechanism for hyperuricemia causing CKD is the ability of uric acid to induce glomerular hypertension. 
It is postulated that the most likely cause of MeN is repeated episodes of acute kidney injury (AKI) related to dehydration, loss of minerals, hypovolemia sometimes accompanied by rhabdomyolysis, systemic inflammation, use of NSAIDs, and oxidative injury [1,2]. CKD may arise from repeated episodes of AKI.

Additionally, excess use of NSAIDs may contribute to MeN [2]. Perturbations in the reninangiotensin system (RAS) due to excessive and repeated losses of salts due to excessive sweating may also be involved in the pathogenesis [7]. Activation of the polyol pathway and increased renal cortical fructose levels during episodes of dehydration may likewise contribute to MeN [4].

Diagnosis of MeN should be considered in at-risk patients who present with a decreased estimated glomerular filtration rate (eGFR) without proteinuria or hematuria and without other causes of CKD [8].

The management of MeN is supportive care involving treatment of signs and symptoms and prevention of progression. Prevention of onset and progression of MeN includes advising patients to drink sodium- and potassium-containing fluids [7]. It has been suggested that unlike in other CKD, MeN patients should avoid angiotensin-converting enzyme (ACE) inhibitors or angiotensin receptor blockers (ARBs). This is because ACE inhibitors and ARBs may result in blockade of the RAS and may predispose individuals to AKI secondary to hypovolemia, subsequently increasing the risk of MeN. The avoidance of sugary beverages and fructose-containing fluids has also been suggested to reduce onset and progression of MeN [7].

\section{Conclusions}

In the face of global warming and increasing number of unexplained CKD cases, there is a need for a high index of suspicion for MeN in patients who live or grew up in the tropics presenting with CKD especially with investigation findings revealing no abnormality. Also, identifying and instituting appropriate preventive lifestyle pattern could prevent the onset and potentially slow down the progression of MeN.

\section{Additional Information \\ Disclosures}

Human subjects: Consent was obtained by all participants in this study. Conflicts of interest: In compliance with the ICMJE uniform disclosure form, all authors declare the following:

Payment/services info: All authors have declared that no financial support was received from any organization for the submitted work. Financial relationships: All authors have declared that they have no financial relationships at present or within the previous three years with any organizations that might have an interest in the submitted work. Other relationships: All authors have declared that there are no other relationships or activities that could appear to have influenced the submitted work.

\section{References}

1. Brooks DR, Ramirez-Rubio O, Amador JJ: CKD in Central America: a hot issue . Am J Kidney Dis. 2012, 59:481-484. 10.1053/j.ajkd.2012.01.005

2. Trabanino RG, Aguilar R, Silva CR, Mercado MO, Merino RL: End-stage renal disease among patients in a referral hospital in El Salvador. [Article in Spanish]. Rev Panam Salud Publica. 2002, 12:202-206.

3. Cuadra SN, Jakobssson K, Hogstedt C, et al.: Chronic kidney disease in Central America: assessment of current knowledge and feasibility for regional research collaboration in Central America. SALTRA Technical Series on Work \& Health. SALTRA, Heredia, Costa Rica; 2009. 


\section{Cureus}

2:73-89.

4. Wesseling C, Crowe J, Hogstedt C, Jakobsson K, Lucas R, Wegman D: Mesoamerican nephropathy: report from the first international research workshop on MeN. IRETUNA/SALTRA. SALTRA, San Jose, Costa Rica; 2013. 239.

5. Wegman D, Crowe J, Hogstedt C, Jakobsson K, Wesseling C: Mesoamerican nephropathy: report from the second international research workshop on MeN. Central American Institute for Studies on Toxic Substances (IRET-UNA) Program on Work, Environment and Health in Central America (SALTRA). SALTRA/IRET-UNA, Heredia, Costa Rica; 2016. 1-193.

6. VanDervort DR, López DL, Orantes CM, Rodríguez DS: Spatial distribution of unspecified chronic kidney disease in El Salvador by crop area cultivated and ambient temperature. MEDICC Rev. 2014, 16:31-38. https://www.ncbi.nlm.nih.gov/pubmed/24878647

7. Wijkström J, Leiva R, Elinder CG, et al.: Clinical and pathological characterization of mesoamerican nephropathy: a new kidney disease in Central America. Am J Kidney Dis. 2013, 62:908-918. 10.1053/j.ajkd.2013.05.019

8. Elinder C-G, Wernerson AO: Mesoamerican nephropathy. UpToDate. 2017, Accessed: May 16, 2018: https://www.uptodate.com/contents/mesoamerican-nephropathy. 